\title{
Co-Medication and Nutrition in Hepatocellular Carcinoma: Potentially Preventative Strategies in Hepatocellular Carcinoma
}

\author{
Alexander Kusnik ${ }^{a}$ b Nicole Hunter ${ }^{c}$ Erik Rasbach ${ }^{a}$ Thomas Miethke ${ }^{c}$ \\ Christoph Reissfelder $^{a} \quad$ Matthias Philip Ebert ${ }^{a}{ }^{b} \quad$ Andreas Teufel $^{a}$, b \\ ${ }^{a}$ Department of Medicine II, University Medical Center Mannheim, Medical Faculty Mannheim, Heidelberg

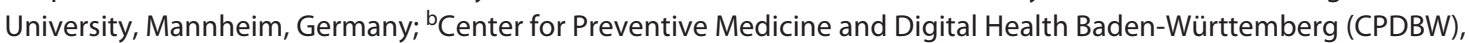 \\ Medical Faculty Mannheim, Heidelberg University, Mannheim, Germany; Institute of Medical Microbiology and \\ Hygiene, Medical Faculty Mannheim, Heidelberg University, Mannheim, Germany
}

\section{Keywords}

Acetylsalicylic acid · Aspirin · Co-medication ·

Hepatocellular carcinoma · Liver cancer · Metformin ·

Prevention · Statin

\begin{abstract}
Background: Hepatocellular carcinoma (HCC) is one of the leading causes of cancer-related death worldwide, with about 841,000 new cases and 782,000 deaths annually. Given the clearly defined population at risk, mostly patients with liver cirrhosis, prevention of HCC could be highly effective. Summary: Besides regular ultrasound surveillance, numerous publications have suggested protective effects of diverse drugs and nutrients. However, none of those preventive options has made it into clinical routine or practice guidelines. We therefore summarize the current status of preventive effects of drugs such as statins, acetylsalicylic acid (ASA), and metformin, but also dietary aspects and nutrients such as coffee, tea, and vitamin D supplementation. A successful implementation of some of these strategies may potentially lead to improved prevention of HCC development in patients with liver cirrhosis. Key Messages: Accumulating data suggest that particularly ASA, antidiabetic therapies, and statins may substantially decrease HCC incidence in patients at risk.

(c) 2021 S. Karger AG, Basel
\end{abstract}

\section{Background}

Hepatocellular carcinoma (HCC) is one of the leading causes of cancer-related death worldwide with about 841,000 new cases and 782,000 deaths annually [1]. Currently, the HEPAHEALTH Report of the European Society for the Study of the Liver (EASL) assumes a prevalence of 6-12 patients per 100,000 inhabitants. According to the Global Cancer Observatory by the World Health Organization (WHO), these numbers are likely to increase within the upcoming years to $>1,300,000$ cases by 2040 [2]. In the USA, HCC is the most rapidly increasing cancer-associated cause of death, and the rate of death increased by $43 \%$ between 2000 and $2016[3,4]$. This trend was also observed in most European countries, whereas a decrease was only seen in southern Europe [5]. Reduced mortality rates were also observed in East Asian countries and Japan.

Cirrhosis is the strongest predictor of HCC incidence and mortality [6], as $80-90 \%$ of all HCC patients have an underlying chronic liver disease [7]. Despite this clearly defined population at risk, only $30 \%$ of all HCC cases are currently diagnosed early [8]. This has fatal consequences for these patients, since late diagnosis of HCC, stage BCLC C or D, significantly reduces the 5-year survival rate to a maximum of $10-16 \%[9,10]$. The prevention of

\footnotetext{
Karger"
} 
Fig. 1. Graphical summary of potentially preventive strategies in HCC. Arrows indicate summarized effects with regular intake of the substance. Down arrow indicates decreased HCC risk, and side arrow indicates inconclusive evidence. RAS, renin-angiotensin system; PUFAs, polyunsaturated fatty acids; HCC, hepatocellular carcinoma; ASA, acetylsalicylic acid.

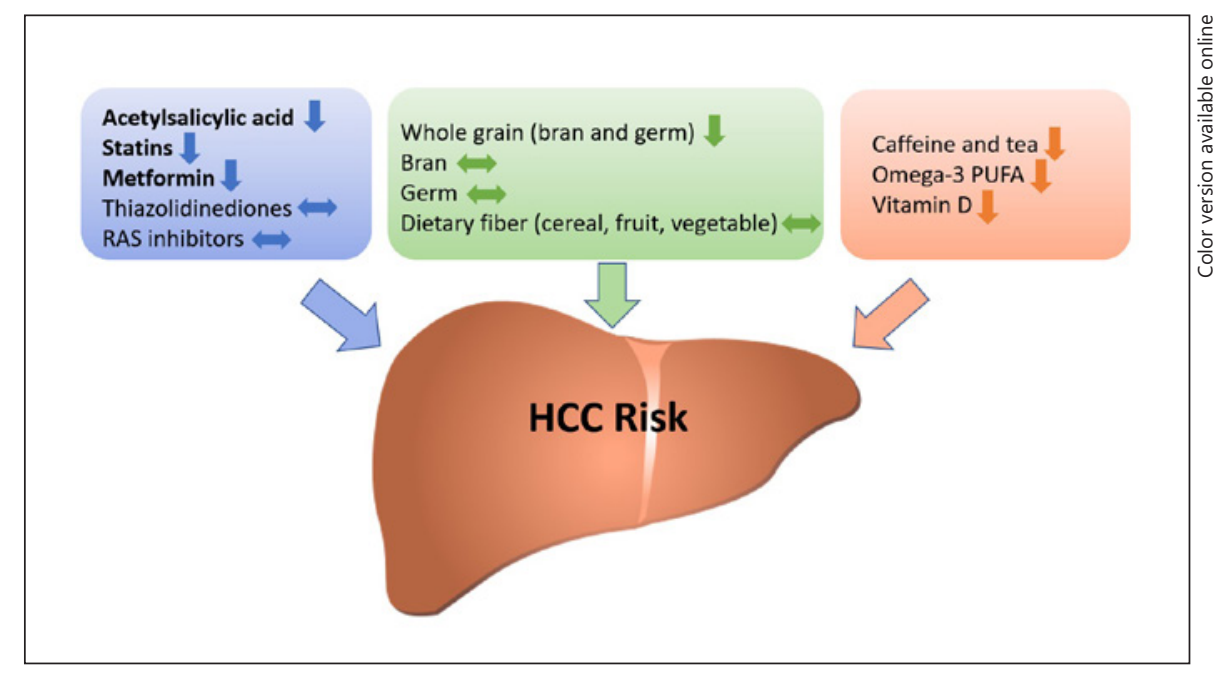

HCC development is therefore of essential importance in patients with liver cirrhosis. In addition to effective vaccination campaigns against hepatitis B [11], avoidance of unsafe blood transfusions [12], and hepatitis $C$ eradication [13], protective effects of individual foods, drugs, and chemicals are described. Interestingly, there is now an increasing number of publications reporting the preventive potential of various medications such as statins, ASA, and metformin, and nutritional substances such as coffee (Fig. 1).

\section{Acetylsalicylic Acid}

Platelets have an enormous effect on the immune modulation of the liver. In a chronic hepatitis B mouse model, Sitia et al. [14] showed that platelet aggregation inhibitors prevented or at least reduced liver inflammation, fibrosis, and HCC development. In addition, acetylsalicylic acid (ASA, Aspirin) has been shown to inhibit glucose uptake by downregulating glucose transporter 1 and to significantly reduce reactive oxygen species and glucose consumption in hepatoma cells [15]. ASA-related inhibition of COX-2 also counteracts the $\mathrm{WNT} / \beta$ catenin pathway [16], ultimately leading to decreased cell proliferation. Finally, recent studies indicated that ASA can suppress collagen deposition and subsequent liver tumor growth. This is mediated by targeting the NF- $\kappa \mathrm{B} / \mathrm{P} 4 \mathrm{HA} 2$ and LMCD1-AS1/let-7g/P4HA2 axes [17].

These molecular effects on cancer and liver cancer biology well translated into protective effects in patients at risk to develop HCC, particularly those suffering from liver cirrhosis. In a recent study, Simon et al. [18] evaluated the protective impact of ASA in patients with HBV or HCV infection based on nationwide Swedish registries. At a median follow-up period of 7.9 years, the estimated cumulative incidence of HCC was $4.0 \%$ for the ASA group and 8.3\% for the non-ASA group. Similar results were found by Lee et al. [19] in a Taiwan nationwide cohort study investigating patients with chronic hepatitis B. Furthermore, pooled analysis of 2 prospective US health-care cohorts by Simon et al. [20] revealed a doseand duration-dependent benefit in a healthy population. Significantly lower HCC risk was observed with increasing the duration of the use of 1.5 or more standard dose ASA tablets $(325 \mathrm{mg})$ per week for 5 or more years.

However, randomized controlled trials are not available. Also, beyond HCC, RCTs for ASA investigating potential benefit in diverse cancer patients provided conflicting results. In a large meta-analysis of 8 randomized trials for patients with solid cancers, Rothwell et al. [21] showed a decreased 20-year risk of cancer-related death in ASA groups compared with control groups (all solid cancers, HR 0.80, $p<0.0001$; gastrointestinal cancers, $0.65, p<0.0001)$. In contrast, a more recent meta-analysis including 16 RCTs with $>100,000$ patients did not find any significant reductions in solid cancer-related mortality or cancer incidence with the use of ASA [22]. Furthermore, the study observed higher bleeding rates in patients taking ASA, and its use was therefore not recommended. With just recently another large study from Korea supporting protective effects of ASA (and statins [23]), these studies highlight that the use of ASA primary prevention 
is most likely only beneficial for patients with considerable risk for HCC.

\section{Statins in the Prevention of HCC}

Statins, inhibiting 3-hydroxy-3-methylglutaryl coenzyme A (HMG-CoA) reductase, are widely used for treatment of hyperlipidemia $[24,25]$. In addition, they have been established to be essential for primary and secondary prevention of cardiovascular diseases like coronary artery disease, peripheral artery disease, and stroke [26]. Several studies have demonstrated the protective effects of statins in patients with chronic liver disease, especially related to HBV and HCV infection [27-31]. Five recent meta-analyses by Zhong et al. [32], Jeong et al. [33], Facciorusso et al. [34], Li et al. [35], and Islam et al. [36] support the protective effects of statins in primary liver cancer risk, especially in high-risk individuals. Zhong et al. [32] evaluated 25 studies including $>2$ million individuals and indicated a dose-dependent inverse correlation between statin intake and primary liver cancer risk (RR, 0.60 , 95\% confidence interval $[\mathrm{CI}]=0.53-$ 0.69 ), which was even more distinctive in patients with viral hepatitis and diabetes. Jeong et al. [33] performed an umbrella review of 43 meta-analyses investigating the association between statin use and 18 types of cancer. In classifying the evidence level, no cancer type showed convincing evidence as no statistical significance could be calculated, but a suggestive preventive effect was described for esophageal, blood, leukemia, and liver cancer. Facciorusso et al. [34] included 1,925,964 patients into their meta-analysis, showing that lipophilic statins were associated with HCC prevention ( $\mathrm{HR}, 0.49,95 \% \mathrm{CI}=0.39-0.62$ ). However, the underlying effects seem to be dose-dependently mediated [34]. Islam et al. [36] identified 24 studies comprising 59,073 patients, and their meta-analysis also revealed an association between statin medication and reduced risk of HCC development ( $R R, 0.54,95 \% \mathrm{CI}=0.47-0.61$ ). Li et al. [35] recently published a meta-analysis to elucidate the role of statins in the development of HCC in patients with HBV or HCV infection. Therein, 13 studies comprising 519,707 patients were included and statin medication was shown to be associated with reduced risk of HCC (RR, 0.54, 95\% CI = 0.44-0.66; $p<0.001)$. Remarkably, stratified subgroup analyses revealed a consistent association between statin use and reduced risk of HCC development in patients with or without (i) HBV or HCV infection, (ii) age $\geq 50$ years, (iii) male or female gender, (iv) cirrhosis, and (v) diabetes. These findings underline the presumed role of statins in the prevention of $\mathrm{HCC}$, with special respect to patients with $\mathrm{HBV}$ or $\mathrm{HCV}$ infection, indicating the need for validation in future randomized controlled trials.

Statins may exhibit their protective effects through diverse mechanisms. First, statins decrease angiotensin IIinduced inflammation and oxidative stress in the liver by reducing the expression of TGF- $\beta 1$, IL- 6 , and Rac1 [37]. Moreover, they decrease portal hypertension [38] via increased endothelial nitric oxide synthase expression [3941] and increased vasoprotective effects through induction of transcription factor Kruppel-like factor 2 [42]. In addition, by inhibiting the RhoA/Rho-kinase pathway, statins deactivate hepatic stellate cells and improve hepatic fibrogenesis, resulting in less proliferation and apoptosis [43].

Second, multiple cancer pathways are targeted by statins, resulting in decreased deterioration of apoptosis, decreased tumor initiation, and inhibition of tumor growth. Among those pathways are the RAF/MEK/ERK pathway [44] or the MYC-phosphorylation pathway [45]. Third, statins are believed to directly inhibit $\mathrm{HBV} / \mathrm{HCV}$ associated viral replication and therefore work synergistically with nucleos(t)ide analogs [46-48].

These molecular mechanisms also translate into efficacy in HCC prevention. Besides contributing to greater survival in patients with cirrhosis $[42,49,50]$, multiple randomized controlled trials also indicate a benefit in advanced stages of HCC [51, 52]. Graf et al. [52] combined palliative transarterial chemoembolization with pravastatin $(20-40 \mathrm{mg} /$ day) in 52 patients and compared it to 131 patients who received chemoembolization alone. The combined treatment of chemoembolization and pravastatin improved survival of patients with advanced HCC (20.9 months, 95\% CI 15.5-26.3, $p=0.003$ ) compared to treatment with transarterial chemoembolization alone (12.0 months, 95\% CI 10.3-13.7). Similar evidence was found in 2001 by Kawata et al. [51] who randomized 83 patients to standard treatment of HCC (transcatheter arterial embolization followed by oral 5-FU $200 \mathrm{mg}-1$ day for 2 months) with or without pravastatin. They also showed a prolonged survival in combination treatment. Other studies also indicated a benefit with the addition of a statin to palliative chemotherapy in HCC [53], decreased rate of recurrence after initial resection [54], and improved recurrence-free survival with the use of a perioperative statin in patients undergoing curative liver resection [55]. A case-control study performed by Lai et al. [56] on a Taiwanese population further confirmed a $28 \%$ decreased risk of HCC with the use of statins. 


\section{Antidiabetic Medications}

Antidiabetic medications have been suggested to modify the risk of cancer in patients with diabetes. Specifically metformin treatment was linked to a decreased risk of HCC in patients with diabetes $[57,58]$. Metformin is a biguanide derivative that ultimately leads to inhibition of the mTOR pathway [58], potentially decreasing the risk of HCC since disruption of the mTOR pathway is seen in $40-50 \%$ of HCCs [58]. Additionally, thiazolidinediones (TZDs), or peroxisome proliferator activated receptor- $\gamma$ agonists, exert anticancer effects by inhibition of the ubiquitin-proteasome system and the ERK pathway [58, 59]. Activation of peroxisome proliferator activated receptor- $\gamma(\operatorname{PPAR}-\gamma)$ is able to inhibit HCC cell proliferation and tumor growth, and induces an inhibitory effect on HCC metastasis [59]. The systematic reviews and meta-analyses by Zhou et al. [60] and Decensi et al. [57] both suggest the strongest protective association between metformin and HCC risk. Translation of molecular data into clinical benefit was evaluated by Zhou et al. [60] in a meta-analysis (1 RCT and 12 observational studies) with a total of 481,358 subjects and 240,678 HCC cases receiving at least 2 different antidiabetic medications. Direct comparisons showed that the use of metformin (RR, 0.49, 95\% CI 0.25-0.97) was associated with a significant risk reduction of HCC. In addition, metformin was demonstrated to be more beneficial than sulfonylurea (RR, 0.45 , 95\% CI $0.27-0.74$ ) or insulin (RR, 0.28 , 95\% CI 0.17-0.47) medication [60]. TZDs were also reported to exert beneficial effects against HCC [60]. A meta-analysis of 19 studies involving 550,882 diabetic subjects suggested that metformin improved survival of HCC patients (OR, $0.52,95 \%$ CI, $0.40-0.68, p<0.001$ ) compared to non metformin users [61]. This protective effect was evident in all subgroup analyses, except for 2 randomized controlled trials that found no significant difference $(\mathrm{OR}, 0.84 \mathrm{CI}$, $0.10-6.83 ; p=0.871$ ) [61]. Results involving TZDs are less consistent, and there is a definite need for more randomized controlled trials and pathophysiological studies to determine a role for both of these antidiabetic medications as a chemopreventive strategy in HCC [60].

\section{Renin-Angiotensin System Inhibitors}

Renin-angiotensin system (RAS) inhibitors, including angiotensin-converting enzyme inhibitors (ACE-Is) and angiotensin II type 1 receptor blockers (ARBs), have been explored as potential adjuvant therapies for HCC due to their antiangiogenic and antifibrogenic activity $[62,63]$.
ACE-Is and ARBs increase the angiotensin I-VII levels, resulting in the activation of the Mas receptor and subsequent inhibition of cell proliferation and angiogenesis [64, 65].

A systematic review involving 31 studies showed that in humans, RAS inhibitors used alone or in combination suppressed the cumulative HCC recurrence but did not prolong patient survival [62]. A significant protective effect of ACE-Is was only observed when used in combination with vitamin $\mathrm{K}$ or branched-chain amino acids. However, no significant increase in overall survival was observed [62]. Looking at the individual studies, all experimental studies displayed beneficial effects of RAS inhibitors on hepatocarcinogenesis [62]. At the same time, several retrospective observational studies showed conflicting results with respect to survival [62]. Large-scale studies demonstrating chemoprotective effects of ACE-Is and ARBs against HCC remain lacking. A nationwide high-risk cohort study in Taiwan compared the chemoprotective effects of ACE-Is and ARBs in high-risk populations with HBV or HCV infection [65]. In this population, ACE-I or ARB use in the $\mathrm{HBV}$ and $\mathrm{HCV}$ cohorts was not associated with protective effectiveness under standard dosages [65]. However, direct-acting antiretroviral therapy was not accessible in these cohorts, and whether liver fibrosis could be resolved using ACE-Is and ARBs was not investigated [65].

\section{Dietary Agents for Prevention of HCC}

\section{Caffeine and Tea}

Coffee consumption was repeatedly associated with a dose-dependent reduced risk of HCC, regardless of the etiology of the underlying chronic liver disease $[58,66]$. A meta-analysis of 18 cohorts involving more than 2 million participants and 2,905 cases, and 8 case-control studies involving 1,825 cases and 4,652 controls observed that increasing coffee consumption by 2 cups per day reduced the risk of HCC by $35 \%$ (RR, 0.65, 95\% CI 0.59-0.72) [67]. The association was not significantly different in participants with pre-existing chronic liver disease at baseline or for the main exposures for HCC including high alcohol consumption, smoking, high BMI, T2DM, and HBV/HCV [67]. In addition to coffee consumption, benefits were also seen for the regular use of tea. However, data concerning the use of decaffeinated coffee were rather conflicting $[67,68]$. A European multicenter, prospective cohort study included $>450,000$ individuals and did not find an apparent hepatoprotective effect with the regular use of decaffeinated coffee [68]. In contrast, a meta-analysis conducted by Kennedy et al. [67] indicated a mild protective effect resulting in associ- 
ated reduction of $14 \%$ (RR, $0.86,95 \%$ CI $0.74-1.00)$ [67, 68]. Caffeine reduces HCC cell proliferation and its compounds, cafestol and kahweol, increase the activity of phase 2 liver enzymes to increase the metabolism and excretion of carcinogens $[58,67]$. Other compounds, such as polyphenols, may ameliorate oxidative DNA damage, which potentially explains the hepatoprotective effect of tea, especially green tea $[67,69,70]$.

\section{Omega-3 Polyunsaturated Fatty Acids}

Fish consumption, a rich source of omega-3 polyunsaturated fatty acids (PUFAs), has been associated with a reduced risk of HCC. A population-based prospective study in Japan involving $>90,000$ subjects investigated the relationship between fish/omega-3 PUFA consumption and the risk of HCC [71]. The authors demonstrated that consumption of fish with high omega-3 PUFA concentration was associated with a decreased risk of HCC [71]. A meta-analysis of 10 studies found that fish consumption decreased the risk of HCC by $35 \%$ and that dietary intake of omega-3 PUFAs was associated with a decreased risk of HCC [72]. Omega-3 PUFAs may inhibit HCC growth through simultaneous inhibition of COX-2 and $\beta$-catenin [73].

\section{Fruits, Vegetables, and Plants}

Dietary factors are likely to play an important role in the prevention of HCC. Patients diagnosed with nonalcoholic fatty liver disease tend to be obese and exhibit insulin resistance $[74,75]$. Some of these patients will progress into advanced liver disease, cirrhosis, and HCC [76]. As obesity is considered a major driver of hepatocellular cancer [77], dietary strategies are urgently needed as the global prevalence of NAFLD will most likely continue to rise [75, 78]. Yang et al. [79] examined the impact of long-term intake of whole grain (bran and germ) and dietary fiber (cereals, fruits, and vegetables) on HCC development. Their data indicated that increased whole grain intake correlated significantly with lower HCC risk. Regular consumption of dietary fiber did not significantly reduce HCC risk: only a suggestive inverse association was found for cereal fiber intake. Turati et al. [80] assessed the role of a Mediterranean diet and HCC risk; close adherence to a Mediterranean diet was inversely associated with HCC risk. Contrasting the previously mentioned study, only regular consumption of vegetables and cereals was associated with a significant reduction in HCC risk. No association was found for other components of a Mediterranean diet, highlighting the importance of accurately recognizing the optimal components of diet for the prevention of
HCC. Despite these conflicting results, one can speculate that regular intake of grains and dietary fiber may prove beneficial as it opposes known risk factors for HCC like diabetes mellitus type $2[81,82]$ and obesity $[77,83]$.

\section{Vitamin D}

Vitamin D is considered a steroid hormone stimulating the absorption of calcium and phosphorus in the gastrointestinal tract to increase bone mineral content and remodeling [84]. In addition, it plays a role in innate and adaptive immune systems as well as in other extra-skeletal functions [85]. In the blood, vitamin D is mainly composed of $25(\mathrm{OH}) \mathrm{D}_{3}$ (vitamin $\mathrm{D}_{3}$ ) [84]. Low serum levels of vitamin $\mathrm{D}_{3}$ were associated with the risk of $\mathrm{HCC}$ in patients with chronic hepatitis B infection [86]. A prospective cohort study conducted by Wong et al. [87] involved 426 patients with chronic hepatitis $\mathrm{B}$ and observed the adverse effects of vitamin D deficiency on the outcomes of patients. At baseline, $82 \%$ of patients had vitamin $\mathrm{D}$ deficiency. The 15 -year cumulative incidence rate of clinical events, including HCC, progression of cirrhosis, and death, was $25.5 \%$ in patients with vitamin D deficiency compared to $11.1 \%$ in patients with normal levels of vitamin D [87]. As an independent factor, vitamin D concentration is negatively correlated with serum HBV levels and viral load [88]. A phase IV interventional trial of vitamin $\mathrm{D}_{3}$ supplementation for the prevention of HCC in patients with chronic hepatitis B infection is currently underway (NCT02779465). Aside from chronic hepatitis B infection, low levels of 25-hydroxyvitamin D $(25[\mathrm{OH}] \mathrm{D})$ were also associated with increased liver damage and mortality in alcoholic liver disease [89] and inversely associated with the risk of HCC [90].

\section{Summary}

Given the global burden and increase of HCC, improvement of preventive strategies is urgently needed. Data on co-medications such as metformin, statins, or ASA suggested preventive efficacy in patients at risk. Furthermore, it is hoped that novel drugs such as cenicriviroc, elafibranor, or obeticholic acid delineating the mechanisms of hepatic fibrosis and oncogenesis in NASH will further improve HCC prevention. Coffee, tea, and omega-3 PUFAs were also suggested to be useful lifestyle interventions potentially displaying mild protective effects, whereas negative side effects on long-term use are not described. Finally, vitamin $\mathrm{D}$ supplementation may be useful. 
More randomized clinical evidence is still needed to verify these results. However, as we may not see any random controlled trials for most of these substances in the future and given the simplicity of these measurements, substances or nutrients with a solid retrospective data basis should increasingly be considered for patients at risk for HCC.

\section{Acknowledgements}

The Clinical Cooperation Unit Healthy Metabolism at the Center for Preventive Medicine and Digital Health Baden-Württemberg $\left(\mathrm{CPD}^{\mathrm{BW}}\right)$ is funded by a grant from the state of Baden-Württemberg, Germany. Also, the project Baden-Wüttemberg Center for Digital Early Detection and Prevention (BW-ZDFP) received funding by the state of Baden-Württemberg.

\section{Statement of Ethics}

The authors have no ethical conflicts to disclose.

\section{Conflict of Interest Statement}

The authors have no conflict of interest to disclose.

\section{Funding Sources}

The Clinical Cooperation Unit Healthy Metabolism at the Center for Preventive Medicine and Digital Health Baden-Württemberg $\left(\mathrm{CPD}^{\mathrm{BW}}\right)$ is funded by a grant from the state of Baden-Württemberg, Germany. Also, the project Baden-Württemberg Center for Digital Early Detection and Prevention (BW-ZDFP) received funding by the state of Baden-Württemberg.

\section{Author Contributions}

All authors made substantial contributions to the conception or design of the work and revised it critically for important intellectual content. All authors also gave their final approval of the version to be published and are accountable for all aspects of the work, and ensure that questions related to the accuracy or integrity of any part of the work are appropriately investigated and resolved.

\section{References}

1 Ampuero J, Romero-Gomez M. Prevention of hepatocellular carcinoma by correction of metabolic abnormalities: role of statins and metformin. World J Hepatol. 2015;7(8): 1105-11.

2 Ferlay J, Colombet M, Soerjomataram I, Mathers C, Parkin DM, Piñeros M, et al. Estimating the global cancer incidence and mortality in 2018: GLOBOCAN sources and methods. Int J Cancer. 2019;144(8):1941-53.

3 Bray F, Ferlay J, Soerjomataram I, Siegel RL, Torre LA, Jemal A. Global cancer statistics 2018: GLOBOCAN estimates of incidence and mortality worldwide for 36 cancers in 185 countries. CA Cancer J Clin. 2018;68(6):394424.

$4 \mathrm{Xu}$ J. Trends in liver cancer mortality among adults aged 25 and over in the United States, 2000-2016: NCHS Data Brief; 2018. p. 1-8.

5 Bertuccio P, Turati F, Carioli G, Rodriguez T, La Vecchia C, Malvezzi M, et al. Global trends and predictions in hepatocellular carcinoma mortality. J Hepatol. 2017;67(2):302-9.

6 Thiele M, Gluud LL, Fialla AD, Dahl EK, Krag A. Large variations in risk of hepatocellular carcinoma and mortality in treatment naïve hepatitis B patients: systematic review with meta-analyses. PLoS One. 2014;9:e107177.

7 El-Serag HB. Hepatocellular carcinoma. N Engl J Med. 2011;365(12):1118-27.

8 Kudo M. Japan's successful model of nationwide hepatocellular carcinoma surveillance highlighting the urgent need for global surveillance. Liver Cancer. 2012;1(3-4):141-3.
9 Wang CY, Li S. Clinical characteristics and prognosis of 2887 patients with hepatocellular carcinoma: a single center 14 years experience from China. Medicine. 2019;98(4): e14070.

10 Wang Z, Gu X, Thrift AP. Factors associated with favorable survival outcomes for Asians with hepatocellular carcinoma: a sequential matching cohort study. PLoS One. 2019; 14(4):e0214721.

11 Chang MH, Chen CJ, Lai MS, Hsu HM, Wu $\mathrm{TC}$, Kong MS, et al. Universal hepatitis B vaccination in Taiwan and the incidence of hepatocellular carcinoma in children. Taiwan childhood hepatoma study group. N Engl J Med. 1997;336(26):1855-9.

12 Thursz M, Fontanet A. HCV transmission in industrialized countries and resource-constrained areas. Nat Rev Gastroenterol Hepatol. 2014;11(1):28-35.

13 Heffernan A, Cooke GS, Nayagam S, Thursz M, Hallett TB. Scaling up prevention and treatment towards the elimination of hepatitis C: a global mathematical model. Lancet. 2019; 393(10178):1319-29.

14 Sitia G, Aiolfi R, Di Lucia P, Mainetti M, Fiocchi A, Mingozzi F, et al. Antiplatelet therapy prevents hepatocellular carcinoma and improves survival in a mouse model of chronic hepatitis B. Proc Natl Acad Sci USA. 2012; 109(32):E2165-72.

15 Liu YX, Feng JY, Sun MM, Liu BW, Yang G, $\mathrm{Bu} \mathrm{YN}$, et al. Aspirin inhibits the proliferation of hepatoma cells through controlling
GLUT1-mediated glucose metabolism. Acta Pharmacol Sin. 2019;40(1):122-32.

16 Kumar M, Zhao X, Wang XW. Molecular carcinogenesis of hepatocellular carcinoma and intrahepatic cholangiocarcinoma: one step closer to personalized medicine? Cell Biosci. 2011;1(1):5.

17 Wang T, Fu X, Jin T, Zhang L, Liu B, Wu Y, et al. Aspirin targets P4HA2 through inhibiting NF- $\mathrm{kB}$ and LMCD1-AS1/let-7g to inhibit tumour growth and collagen deposition in hepatocellular carcinoma. EBioMedicine. 2019;45:168-80.

18 Simon TG, Duberg AS, Aleman S, Chung RT, Chan AT, Ludvigsson JF. Association of aspirin with hepatocellular carcinoma and liverrelated mortality. N Engl J Med. 2020;382(11): 1018-28.

19 Lee TY, Hsu YC, Tseng HC, Yu SH, Lin JT, $\mathrm{Wu}$ MS, et al. Association of daily aspirin therapy with risk of hepatocellular carcinoma in patients with chronic hepatitis B. JAMA Intern Med. 2019;179(5):633-40.

20 Simon TG, Ma Y, Ludvigsson JF, Chong DQ, Giovannucci EL, Fuchs CS, et al. Association between aspirin use and risk of hepatocellular carcinoma. JAMA Oncol. 2018;4(12):168390.

21 Rothwell PM, Fowkes FG, Belch JF, Ogawa H, Warlow CP, Meade TW. Effect of daily aspirin on long-term risk of death due to cancer: analysis of individual patient data from randomised trials. Lancet. 2011;377(9759):3141. 
22 Haykal T, Barbarawi M, Zayed Y, Yelangi A, Dhillon H, Goranta S, et al. Safety and efficacy of aspirin for primary prevention of cancer: a meta-analysis of randomized controlled trials. J Cancer Res Clin Oncol. 2019;145(7): 1795-809.

23 Choi WM, Kim HJ, Ko MJ. Association of aspirin and statin use with hepatocellular carcinoma risk in treatment-naive non-cirrhotic patients with chronic hepatitis B. AASLD The Liver Meet Dig Exp. 2020 Nov.

24 Wang CY, Liu PY, Liao JK. Pleiotropic effects of statin therapy: molecular mechanisms and clinical results. Trends Mol Med. 2008;14(1):37-44.

25 Nayor M, Vasan RS. Recent update to the US cholesterol treatment guidelines: a comparison with international guidelines. Circulation. 2016;133(18):1795-806.

26 Naci H, Brugts JJ, Fleurence R, Tsoi B, Toor $\mathrm{H}$, Ades AE. Comparative benefits of statins in the primary and secondary prevention of major coronary events and all-cause mortality: a network meta-analysis of placebo-controlled and active-comparator trials. Eur J Prev Cardiol. 2013;20(4):641-57.

27 Simon TG, Bonilla H, Yan P, Chung RT, Butt AA. Atorvastatin and fluvastatin are associated with dose-dependent reductions in cirrhosis and hepatocellular carcinoma, among patients with hepatitis $C$ virus: results from ERCHIVES. Hepatology. 2016;64(1):47-57.

28 Simon TG, Duberg AS, Aleman S, Hagstrom $\mathrm{H}$, Nguyen LH, Khalili $\mathrm{H}$, et al. Lipophilic statins and risk for hepatocellular carcinoma and death in patients with chronic viral hepatitis: results from a nationwide swedish population. Ann Intern Med. 2019;171(5):318-27.

29 McGlynn KA, Hagberg K, Chen J, Graubard BI, London WT, Jick S, et al. Statin use and risk of primary liver cancer in the clinical practice research datalink. J Natl Cancer Inst. 2015;107(4):djv009.

30 Chen HH, Lin MC, Muo CH, Yeh SY, Sung $\mathrm{FC}, \mathrm{Kao} \mathrm{CH}$. Combination therapy of metformin and statin may decrease hepatocellular carcinoma among diabetic patients in Asia. Medicine. 2015;94(24):e1013.

31 Hsiang JC, Wong GL, Tse YK, Wong VW, Yip TC, Chan HL. Statin and the risk of hepatocellular carcinoma and death in a hospital-based hepatitis B-infected population: apropensity score landmark analysis. J Hepatol. 2015 63(5):1190-7.

32 Zhong GC, Liu Y, Ye YY, Hao FB, Wang K, Gong JP. Meta-analysis of studies using statins as a reducer for primary liver cancer risk. Sci Rep. 2016;6:26256.

33 Jeong GH, Lee KH, Kim JY, Eisenhut M, Kronbichler A, van der Vliet HJ, et al. Effect of statin on cancer incidence: an umbrella systematic review and meta-analysis. J Clin Med. 2019;8(6):819.

34 Facciorusso A, Abd El Aziz MA, Singh S, Pusceddu S, Milione M, Giacomelli L, et al. Statin use decreases the incidence of hepatocellular carcinoma: an updated meta-analysis. Cancers. 2020:12.
$35 \mathrm{Li}$ X, Liu L, Hu Y. Statin use and the prognosis of patients with hepatocellular carcinoma: a meta-analysis. Biosci Rep. 2020:40.

36 Islam MM, Poly TN, Walther BA, Yang HC, Jack Li YC. Statin use and the risk of hepatocellular carcinoma: a meta-analysis of observational studies. Cancers. 2020:12.

37 Moreno M, Ramalho LN, Sancho-Bru P, Ruiz-Ortega M, Ramalho F, Abraldes JG, et al. Atorvastatin attenuates angiotensin II-induced inflammatory actions in the liver. Am J Physiol Gastrointest Liver Physiol. 2009; 296(2):G147-56.

38 Abraldes JG, Albillos A, Bañares R, Turnes J, González R, García-Pagán JC, et al. Simvastatin lowers portal pressure in patients with cirrhosis and portal hypertension: a randomized controlled trial. Gastroenterology. 2009; 136(5):1651-8.

39 Abraldes JG, Rodríguez-Vilarrupla A, Graupera M, Zafra C, García-Calderó H, GarcíaPagán JC, et al. Simvastatin treatment improves liver sinusoidal endothelial dysfunction in CCl4 cirrhotic rats. J Hepatol. 2007; 46(6):1040-6.

40 Trebicka J, Hennenberg M, Laleman W, Shelest N, Biecker E, Schepke M, et al. Atorvastatin lowers portal pressure in cirrhotic rats by inhibition of RhoA/Rho-kinase and activation of endothelial nitric oxide synthase. Hepatology. 2007;46(1):242-53.

41 Baiges A, Hernández-Gea V, Bosch J. Pharmacologic prevention of variceal bleeding and rebleeding. Hepatol Int. 2018;12(Suppl 1):68-80.

42 Marrone G, Russo L, Rosado E, Hide D, García-Cardeña G, García-Pagán JC, et al. The transcription factor KLF2 mediates hepatic endothelial protection and paracrine endothelial-stellate cell deactivation induced by statins. J Hepatol. 2013;58(1):98-103.

43 Trebicka J, Hennenberg M, Odenthal M, Shir K, Klein S, Granzow M, et al. Atorvastatin attenuates hepatic fibrosis in rats after bile duct ligation via decreased turnover of hepatic stellate cells. J Hepatol. 2010;53(4):702-12.

$44 \mathrm{Wu}$ J, Wong WW, Khosravi F, Minden MD, Penn LZ. Blocking the Raf/MEK/ERK pathway sensitizes acute myelogenous leukemia cells to lovastatin-induced apoptosis. Cancer Res. 2004;64(18):6461-8.

45 Cao Z, Fan-Minogue H, Bellovin DI, Yevtodiyenko A, Arzeno J, Yang Q, et al. MYC phosphorylation, activation, and tumorigenic potential in hepatocellular carcinoma are regulated by HMG-CoA reductase. Cancer Res. 2011;71(6):2286-97.

46 Bader T, Korba B. Simvastatin potentiates the anti-hepatitis B virus activity of FDA-approved nucleoside analogue inhibitors in vitro. Antiviral Res. 2010;86(3):241-5.

47 Delang L, Paeshuyse J, Vliegen I, Leyssen P, Obeid S, Durantel D, et al. Statins potentiate the in vitro anti-hepatitis $C$ virus activity of selective hepatitis $C$ virus inhibitors and delay or prevent resistance development. Hepatology. 2009;50(1):6-16.
48 Kim SS, Peng LF, Lin W, Choe WH, Sakamoto N, Kato N, et al. A cell-based, high-throughput screen for small molecule regulators of hepatitis $\mathrm{C}$ virus replication. Gastroenterology. 2007;132(1):311-20.

49 Mohanty A, Tate JP, Garcia-Tsao G. Statins are associated with a decreased risk of decompensation and death in veterans with hepatitis C-related compensated cirrhosis. Gastroenterology. 2016;150(2):430-e1.

50 Abraldes JG, Villanueva C, Aracil C, Turnes J, Hernandez-Guerra M, Genesca J, et al. Addition of simvastatin to standard therapy for the prevention of variceal rebleeding does not reduce rebleeding but increases survival in patients with cirrhosis. Gastroenterology. 2016 150(5):1160-e3.

51 Kawata S, Yamasaki E, Nagase T, Inui Y, Ito $\mathrm{N}$, Matsuda $\mathrm{Y}$, et al. Effect of pravastatin on survival in patients with advanced hepatocellular carcinoma. A randomized controlled trial. Br J Cancer. 2001;84(7):886-91.

52 Graf H, Jüngst C, Straub G, Dogan S, Hoffmann RT, Jakobs T, et al. Chemoembolization combined with pravastatin improves survival in patients with hepatocellular carcinoma. Digestion. 2008;78(1):34-8.

53 Shao JY, Lee FP, Chang CL, Wu SY. Statinbased palliative therapy for hepatocellular carcinoma. Medicine. 2015;94(42):e1801.

54 Kawaguchi Y, Sakamoto Y, Ito D, Ito K, Arita J, Akamatsu N, et al. Statin use is associated with a reduced risk of hepatocellular carcinoma recurrence after initial liver resection. Biosci Trends. 2017;11(5):574-80.

55 Nishio T, Taura K, Nakamura N, Seo S, Yasuchika K, Kaido T, et al. Impact of statin use on the prognosis of patients with hepatocellular carcinoma undergoing liver resection: a subgroup analysis of patients without chronic hepatitis viral infection. Surgery. 2018;163(2): 264-9.

56 Lai SW, Liao KF, Lai HC, Muo CH, Sung FC, Chen PC. Statin use and risk of hepatocellular carcinoma. Eur J Epidemiol. 2013;28(6):485-92.

57 Decensi A, Puntoni M, Goodwin P, Cazzaniga M, Gennari A, Bonanni B, et al. Metformin and cancer risk in diabetic patients: a systematic review and meta-analysis. Cancer Prev Res. 2010;3(11):1451-61.

58 Singh S, Singh PP, Roberts LR, Sanchez W. Chemopreventive strategies in hepatocellular carcinoma. Nat Rev Gastroenterol Hepatol. 2014;11(1):45-54.

$59 \mathrm{Wu}$ CW, Farrell GC, Yu J. Functional role of peroxisome-proliferator-activated receptor $\gamma$ in hepatocellular carcinoma. J Gastroenterol Hepatol. 2012;27(11):1665-9.

60 Zhou YY, Zhu GQ, Liu T, Zheng JN, Cheng $Z$, Zou TT, et al. Systematic review with network meta-analysis: antidiabetic medication and risk of hepatocellular carcinoma. Sci Rep. 2016;6:33743.

61 Ma S, Zheng Y, Xiao Y, Zhou P, Tan H. Metaanalysis of studies using metformin as a reducer for liver cancer risk in diabetic patients. Medicine. 2017;96(19):e6888. 
62 Barone M, Viggiani MT, Losurdo G, Principi $\mathrm{M}$, Leo $\mathrm{AD}$. Systematic review: renin-angiotensin system inhibitors in chemoprevention of hepatocellular carcinoma. World J Gastroenterol. 2019;25(20):2524-38.

63 Zhu Q, Li N, Li F, Zhou Z, Han Q, Lv Y, et al Therapeutic effect of renin angiotensin system inhibitors on liver fibrosis. J Renin Angiotensin Aldosterone Syst. 2016;17(1) 1470320316628717.

64 Sevá Pessôa B, van der Lubbe N, Verdonk K, Roks AJ, Hoorn EJ, Danser AH. Key developments in renin-angiotensin-aldosterone system inhibition. Nat Rev Nephrol. 2013;9(1): 26-36.

65 Ho CM, Lee CH, Lee MC, Zhang JF, Wang JY, $\mathrm{Hu} \mathrm{RH}$, et al. Comparative effectiveness of angiotensin-converting enzyme inhibitors and angiotensin II receptor blockers in chemoprevention of hepatocellular carcinoma: a nationwide high-risk cohort study. BMC Cancer. 2018;18(1):401.

66 Fujiwara N, Friedman SL, Goossens N, Hoshida Y. Risk factors and prevention of hepatocellular carcinoma in the era of precision medicine. J Hepatol. 2018;68(3):526-49.

67 Kennedy OJ, Roderick P, Buchanan R, Fallowfield JA, Hayes PC, Parkes J. Coffee, including caffeinated and decaffeinated coffee, and the risk of hepatocellular carcinoma: a systematic review and dose-response metaanalysis. BMJ Open. 2017;7(5):e013739.

68 Bamia C, Lagiou P, Jenab M, Trichopoulou A, Fedirko V, Aleksandrova K, et al. Coffee, tea and decaffeinated coffee in relation to hepatocellular carcinoma in a European population: multicentre, prospective cohort study. Int J Cancer. 2015;136(8):1899-908.

69 Darvesh AS, Bishayee A. Chemopreventive and therapeutic potential of tea polyphenols in hepatocellular cancer. Nutr Cancer. 2013; 65(3):329-44.

70 Huang WY, Cai YZ, Zhang Y. Natural phenolic compounds from medicinal herbs and dietary plants: potential use for cancer prevention. Nutr Cancer. 2010;62(1):1-20.

71 Sawada N, Inoue M, Iwasaki M, Sasazuki S, Shimazu T, Yamaji T, et al. Consumption of n-3 fatty acids and fish reduces risk of hepatocellular carcinoma. Gastroenterology. 2012; 142(7):1468-75.
72 Gao M, Sun K, Guo M, Gao H, Liu K, Yang C, et al. Fish consumption and n-3 polyunsaturated fatty acids, and risk of hepatocellular carcinoma: systematic review and meta-analysis. Cancer Causes Control. 2015;26(3):36776.

73 Lim K, Han C, Dai Y, Shen M, Wu T. Omega-3 polyunsaturated fatty acids inhibit hepatocellular carcinoma cell growth through blocking beta-catenin and cyclooxygenase- 2 . Mol Cancer Ther. 2009;8(11):3046-55.

74 Vernon G, Baranova A, Younossi ZM. Systematic review: the epidemiology and natural history of non-alcoholic fatty liver disease and non-alcoholic steatohepatitis in adults. Aliment Pharmacol Ther. 2011;34(3):274-85.

75 Younossi ZM, Koenig AB, Abdelatif D, Fazel Y, Henry L, Wymer M. Global epidemiology of nonalcoholic fatty liver disease-Meta-analytic assessment of prevalence, incidence, and outcomes. Hepatology. 2016;64(1):73-84.

76 Anstee QM, Targher G, Day CP. Progression of NAFLD to diabetes mellitus, cardiovascular disease or cirrhosis. Nat Rev Gastroenterol Hepatol. 2013;10(6):330-44.

77 Grohmann M, Wiede F, Dodd GT, Gurzov EN, Ooi GJ, Butt T, et al. Obesity drives STAT-1-dependent NASH and STAT-3-dependent HCC. Cell. 2018;175(5):1289-e20.

78 Perumpail BJ, Khan MA, Yoo ER, Cholankeril G, Kim D, Ahmed A. Clinical epidemiology and disease burden of nonalcoholic fatty liver disease. World J Gastroenterol. 2017;23(47): 8263-76.

79 Yang W, Ma Y, Liu Y, Smith-Warner SA, Simon TG, Chong DQ, et al. Association of intake of whole grains and dietary fiber with risk of hepatocellular carcinoma in US adults. JAMA Oncol. 2019;5(6):879-86.

80 Turati F, Trichopoulos D, Polesel J, Bravi F, Rossi M, Talamini R, et al. Mediterranean diet and hepatocellular carcinoma. J Hepatol. 2014;60(3):606-11.

81 Cho SS, Qi L, Fahey GC Jr, Klurfeld DM. Consumption of cereal fiber, mixtures of whole grains and bran, and whole grains and risk reduction in type 2 diabetes, obesity, and cardiovascular disease. Am J Clin Nutr. 2013; 98(2):594-619.
82 Schwingshackl L, Hoffmann G, Lampousi AM, Knüppel S, Iqbal K, Schwedhelm C, et al. Food groups and risk of type 2 diabetes mellitus: a systematic review and meta-analysis of prospective studies. Eur J Epidemiol. 2017; 32(5):363-75.

83 Kopf JC, Suhr MJ, Clarke J, Eyun SI, Riethoven JM, Ramer-Tait AE, et al. Role of whole grains versus fruits and vegetables in reducing subclinical inflammation and promoting gastrointestinal health in individuals affected by overweight and obesity: a randomized controlled trial. Nutr J. 2018;17(1):72.

84 Ko W-S, Yang Y-P, Shen F-P, Wu M-C, Shih C-J, Lu M-C, et al. The study of correlation between serum vitamin $\mathrm{D}(3)$ concentrations and HBV DNA levels and immune response in chronic hepatitis patients. Nutrients. 2020; 12:1114.

85 Gotlieb N, Tachlytski I, Lapidot Y, Sultan M, Safran M, Ben-Ari Z. Hepatitis B virus downregulates vitamin $\mathrm{D}$ receptor levels in hepatoma cell lines, thereby preventing vitamin $\mathrm{D}$ dependent inhibition of viral transcription and production. Mol Med. 2018;24(1):53.

86 Athuluri-Divakar SK, Hoshida Y. Generic chemoprevention of hepatocellular carcinoma. Ann N Y Acad Sci. 2019;1440(1):23-35.

87 Wong GL, Chan HL, Chan HY, Tse CH, Chim AM, Lo AO, et al. Adverse effects of vitamin D deficiency on outcomes of patients with chronic hepatitis B. Clin Gastroenterol Hepatol. 2015;13(4):783-e1.

88 Farnik H, Bojunga J, Berger A, Allwinn R, Waidmann O, Kronenberger B, et al. Low vitamin D serum concentration is associated with high levels of hepatitis B virus replication in chronically infected patients. Hepatology. 2013;58(4):1270-6.

89 Trépo E, Ouziel R, Pradat P, Momozawa Y, Quertinmont E, Gervy C, et al. Marked 25-hydroxyvitamin D deficiency is associated with poor prognosis in patients with alcoholic liver disease. J Hepatol. 2013;59(2):344-50.

90 Fedirko V, Duarte-Salles T, Bamia C, Trichopoulou A, Aleksandrova K, Trichopoulos D, et al. Prediagnostic circulating vitamin $\mathrm{D}$ levels and risk of hepatocellular carcinoma in European populations: a nested case-control study. Hepatology. 2014;60(4):1222-30. 